\title{
Is visual attention automatically attracted by one's own name?
}

\author{
CLAUS BUNDESEN, SØREN KYLLINGSBAEK, \\ KRISTJÁN JUL HOUMANN, and RUNE MØLLER JENSEN \\ University of Copenhagen, Copenhagen, Denmark
}

\begin{abstract}
Subjects were presented with briefly exposed visual displays of words that were common first names with a length of four to six letters. In the main experiment, each display consisted of four words: two names shown in red and two shown in white. The subject's task was to report the red names (targets), but ignore the white ones (distractors). On some trials the subject's own name appeared as a display item (target or distractor). Presentation of the subject's name as a distractor caused no more interference with report of targets than did presentation of other names as distractors. Apparently, visual attention was not automatically attracted by the subject's own name.
\end{abstract}

When a subject is trained consistently to detect a particular visual stimulus (target) presented among irrelevant stimuli (distractors), the subject may acquire an involuntary tendency to attend to that stimulus whenever it is presented. Such development of automatic attention attraction was demonstrated by Schneider and Shiffrin (1977) and Shiffrin and Schneider (1977) in a classical series of experiments with a stimulus ensemble consisting of individual alphanumeric characters.

In a key experiment, Shiffrin and Schneider (1977, Experiment 4 d) tested subjects who had previously been trained extensively to search for digits (targets) among letters (distractors). The training had been consistent: whenever a digit was presented, it should be attended to; whenever a letter was presented, it should be ignored. The effect of the training was tested in a varied-mapping lettersearch task. The task was to search a particular diagonal of a $2 \times 2$ matrix of characters for letter targets among letter distractors. The other diagonal was to be ignored. The results showed that when digits appeared on the diagonal to be ignored, detection of simultaneous letter targets on the diagonal to be attended to deteriorated. Apparently, although known to be irrelevant and presented in irrelevant display locations, the previous targets (the digits) automatically attracted attention.

To account for the effects of consistent training in search for particular stimuli, Shiffrin and Dumais (1981) and Shiffrin, Dumais, and Schneider (1981) suggested that the "attention strength" (attentional weight) of individual

\footnotetext{
This research was supported by a grant from the International Human Frontier Science Program Organization. We thank Axel Larsen and Hitomi Shibuya for numerous discussions of the work and associate editor Jan Theeuwes and reviewers Richard Shiffrin, Lex van der Heijden, and Steve Yantis for valuable comments on the draft. Correspondence concerning this article should be addressed to Claus Bundesen, Center for Visual Cognition, Psychological Laboratory, University of Copenhagen, Njalsgade 90, DK-2300 Copenhagen S, Denmark (e-mail: bundesen@axp.psl.ku.dk).
}

stimuli changes during training such that stimuli gradually gain in strength when serving as targets and lose in strength when serving as distractors (see also Schneider, Dumais, \& Shiffrin, 1984). Bundesen (1990) developed a quantitative formulation of this hypothesis (for related work, see Schneider, 1985; Shibuya, 1993; Shiffrin \& Czerwinski, 1988; but also see Czerwinski, Lightfoot, \& Shiffrin, 1992).

In Bundesen's (1990) formulation, every stimulus is assigned an attentional weight, which determines the likelihood that the subject will attend to the stimulus. The attentional weight of stimulus $x$ equals

$$
\sum_{j \in R} \eta(x, j) \pi_{j}
$$

where $R$ is a set of perceptual categories, $\eta(x, j)$ is the strength of the sensory evidence that $x$ belongs to category $j$, and $\pi_{j}$ is the pertinence value of category $j$. The pertinence (priority) of category $j, \pi_{j}$, is a measure of the importance of attending to stimuli that belong to category $j$. In Shiffrin and Schneider's experiments, the effects of consistent training in visual search are explained by a mechanism that increments the pertinence value of character type $j, \pi_{j}$, each time a character of type $j$ serves as a target and decrements $\pi_{j}$ each time a character of type $j$ serves as a distractor.

Shiffrin and Schneider's findings suggest that visual attention can be attracted by shapes as complex as individual alphanumeric characters. In terms of Bundesen's (1990) formulation, individual character types can have positive pertinence. Can visual attention also be attracted by shapes as complex as multiletter words? Can visual words have pertinence? To cast light on this problem, we sought to determine whether visual attention was automatically attracted by one's own name. If priority learning can occur for visual words, so that a visual word can attract attention automatically, we would expect a subject's attention to be attracted automatically by his or her own name (cf. Moray, 1959). ${ }^{1}$ 


\section{EXPERIMENT 1}

In Experiment 1, we investigated partial report by color from briefly exposed visual displays. Each display contained four items, each of which was a common Danish first name. Two of the names were shown in red and two were shown in white. The subject's task was to report the red names (targets) but ignore the white ones (distractors). On some trials, the subject's own name appeared as a display item (target or distractor). Would attention be attracted automatically by the subject's own name, so that report of the targets would deteriorate when the name appeared as a distractor?

\section{Method}

Subjects. Twenty subjects ( 10 males and 10 females) participated in the experiment. The subjects had normal or corrected-to-normal visual acuity and normal color vision. Their ages ranged from 17 to 48 years, with a mean of 23 years. Every subject had grown up in Denmark bearing a common Danish first name with a length of four to six letters. None of the subjects were acquainted with the purpose of the experiment.

Names. All items in stimulus displays were common Danish first names with a length of four to six letters. A set of 20 names ( 10 boys' names and 10 girls' names) were used as stimuli for every subject in the practice session. Not one of the 20 names was a first name for any of the subjects.

In the test session, the set of stimuli used with a particular subject depended on the subject's own name. For all subjects, the set was constructed from a fixed pool of 20 new names, which included 10 boys' names and 10 girls' names. The boys' names were Peter, Hans, Erik, John, Mikael, Niels, Henrik, Thomas, Martin, and Jesper. The girls' names were Marie, Inge, Hanne, Tina, Lene, Mette, Louise, Rikke, Julie, and Anne. The stimulus set used with a particular subject was constructed from the pool by changing up to two of the names in the pool. Specifically, if the subject's first name was not found in the pool, a boy's name was replaced by the subject's name if the subject was a male and a girl's name was replaced by the subject's name if the subject was a female. Furthermore, if the pool contained no other name with the same initial letter as the subject's first name, a boy's or a girl's name with the same initial letter as the subject's first name was substituted for a boy's or a girl's name, respectively, with another initial letter. ${ }^{2}$

Displays. The four items in a stimulus display were centered $36 \mathrm{~mm}\left(1.8^{\circ}\right.$ at a viewing distance of $\left.1.2 \mathrm{~m}\right)$ above, below, to the left, and to the right of a fixation point marked by a small $(4 \times 4 \mathrm{~mm})$ blue (CIE $x y$ coordinates of $.16 / .08,9.8 \mathrm{~cd} / \mathrm{m}^{2}$ ) cross. Two of the items were in saturated red (CIE $x y$ coordinates of $.61 / .35,6.6 \mathrm{~cd} / \mathrm{m}^{2}$ ), two were in white (CIE xy coordinates of $.28 / .30,20 \mathrm{~cd} / \mathrm{m}^{2}$ ), and the background was black $\left(0.0 \mathrm{~cd} / \mathrm{m}^{2}\right)$. The items were four-to-sixletter names written in mixed upper- and lowercase (Borland's Turbo-C sans serif font), that is, with uppercase initial letters. Mean height and width of the uppercase initials were $12.3 \mathrm{~mm}\left(0.6^{\circ}\right)$ and $6.2 \mathrm{~mm}\left(0.3^{\circ}\right)$, respectively. Mean height and width of the lowercase letters were $10.0 \mathrm{~mm}\left(0.5^{\circ}\right)$ and $5.6 \mathrm{~mm}\left(0.3^{\circ}\right)$. The overall length of the four-to-six-letter names ranged between 17 and $42 \mathrm{~mm}$, with a mean of $28 \mathrm{~mm}\left(1.3^{\circ}\right)$.

In any display, the four names that appeared were different from each other. The probability that a given set of four members of the stimulus ensemble appeared together in a stimulus display was the same for all four-element subsets of the stimulus set. The probability that the four items were distributed in a particular way over the four possible locations (above, below, left, and right) was also the same for all possible distributions, with one item at each location. Similarly, the probability that the red items were found at a given pair of locations was the same for all pairs of members of the set of four locations.

Masks. Masks consisted of four solid, colored rectangles: one red (CIE $x y$ coordinates of $.61 / .35,6.6 \mathrm{~cd} / \mathrm{m}^{2}$ ) rectangle at each of the two locations where red stimulus items had appeared and one white (CIE $x y$ coordinates of $.28 / .30,20 \mathrm{~cd} / \mathrm{m}^{2}$ ) rectangle at each of the two locations where white stimulus items had appeared. Each rectangle filled an area of $37 \mathrm{~mm}\left(1.8^{\circ}\right)$ vertically $\times 63 \mathrm{~mm}\left(3.0^{\circ}\right)$ horizontally, which covered up the location at which the corresponding stimulus item had appeared.

Procedure. The subject was seated in front of a computer-driven video screen (VGA with a refresh rate of $60 \mathrm{~Hz}$ ) at a viewing distance of $1.2 \mathrm{~m}$ in a semidarkened room. The fixation cross was continuously visible at the center of the screen.

Each trial was initiated by the subject. When adequately fixated, the subject pressed a key to produce an immediate exposure of the stimulus display. Exposure duration was $150 \mathrm{msec}$. When stimulus exposure terminated, the mask was exposed for a period of $500 \mathrm{msec}$.

The subject's task was to report as many targets (red names) as possible from the stimulus display and to ignore the distractors (white names). The instruction stated that a name should be reported if, and only if, the subject was "fairly certain" that the name had been correctly identified. The location of the name should not be reported. The report was spoken by the subject and written down by the experimenter. When the report had been recorded, the experimenter gave a spoken ready signal ("Klar!") to the subject, and the subject initiated the next trial. On the average, a trial took about $15 \mathrm{sec}$.

Design. Subjects participated individually in a practice session followed by a test session. The practice session was used to familiarize the subjects with the apparatus and procedure. The session comprised 50 trials, which were administered as two blocks of 25 trials with a short break between blocks. Because 4 names appeared per trial, a total of 200 name tokens were presented during the session. The 200 tokens consisted of 10 tokens of each of the 20 names in the stimulus ensemble used for practice. Among the 10 tokens, 5 were red (targets) and 5 were white (distractors).

The test session comprised 200 trials, which were administered as eight blocks of 25 trials with short breaks between blocks. The 800 name tokens that appeared in total consisted of 40 tokens of each of the 20 names that formed the stimulus ensemble for the test session. Among the 40 tokens, 20 were red and 20 were white.

The serial order of trials within sessions was random. All randomizations were done independently for the 20 subjects.

\section{Results}

Proportion correct. The main results are shown in Table 1. For $i=1,2, \ldots, 20$, row $i$ shows the name and the results of subject $i$. The results include proportion correct for the subject's own name (i.e., the observed probability that the subject reported his or her own name correctly when it appeared as a target), proportion correct for the other target in displays in which the subject's name appeared as a target, proportion correct for individual targets in displays in which the subject's name appeared as a distractor, and proportion correct for individual targets in displays from which the subject's name was absent. Group means (mean proportions across the 20 subjects) are shown in Row 21.

As can be seen in Table 1, the group mean proportion correct for displays with the subject's name as a distractor (.56) was virtually the same as the group mean proportion correct for displays without the subject's name (.57). A statistical analysis of the results for individual subjects supported the null hypothesis that performance was the 
Table 1

Subjects' Names and Proportions of Correct Reports for These, for Other Targets in Displays With the Name as a Target, for Targets in Displays With the Name as a Distractor, and for Targets in Displays Without the Name (Experiment 1)

\begin{tabular}{|c|c|c|c|c|c|}
\hline \multirow[b]{3}{*}{ Subject } & \multirow[b]{3}{*}{ Name } & \multicolumn{4}{|c|}{ Display Type } \\
\hline & & \multicolumn{2}{|c|}{ Own Name as Target } & \multirow{2}{*}{$\begin{array}{c}\text { Own Name as } \\
\text { Distractor } \dagger\end{array}$} & \multirow{2}{*}{$\begin{array}{c}\text { Own Nam } \\
\text { Absent } \ddagger\end{array}$} \\
\hline & & Own Name* & Other Target* & & \\
\hline 1 & Poul & .65 & .45 & .38 & .44 \\
\hline 2 & Thomas & .95 & .60 & .53 & .57 \\
\hline 3 & Gitte & .90 & .50 & .50 & .50 \\
\hline 4 & Niels & .45 & .65 & .73 & .55 \\
\hline 5 & Hanne & .30 & .70 & .53 & .57 \\
\hline 6 & Henrik & .85 & .45 & .48 & .51 \\
\hline 7 & Jesper & .55 & .55 & .45 & .48 \\
\hline 8 & Anja & .95 & .55 & .58 & .66 \\
\hline 9 & Mette & .80 & .45 & .85 & .72 \\
\hline 10 & Jesper & .45 & .30 & .28 & .39 \\
\hline 11 & Mikael & .35 & .45 & .55 & .52 \\
\hline 12 & Lotte & .55 & .65 & .35 & .51 \\
\hline 13 & Jens & .60 & .80 & .73 & .68 \\
\hline 14 & Karen & .80 & .70 & .60 & .66 \\
\hline 15 & Louise & .70 & .50 & .58 & .64 \\
\hline 16 & Anne & .55 & .30 & .40 & .39 \\
\hline 17 & Lisa & .50 & .35 & .45 & .41 \\
\hline 18 & Peter & 1.00 & .80 & .85 & .81 \\
\hline 19 & Jesper & .95 & .65 & .80 & .79 \\
\hline 20 & Heidi & .45 & .60 & .58 & .59 \\
\hline Group & & .67 & .55 & .56 & .57 \\
\hline
\end{tabular}

*Proportions are based on 20 cases per subject. ${ }^{+}$Proportions are based on 40 cases per subject. $\quad$ †Proportions are based on 320 cases per subject.

same independently of whether a subject's own name appeared as a distractor. Thus, for each of the 20 subjects, we carried out a chi-square test of the hypothesis that the theoretical proportion correct for displays with the subject's name as a distractor was the same as the theoretical proportion correct for displays without the subject's name. Not one of the 20 tests yielded significance at a level of .05 . By summing the 20 statistics, $\chi^{2}(20)=13.4, p>.50$.

Consider performance for displays in which the subject's name appeared as a target. The group mean proportion correct for the other target in such displays was nearly the same (.55) as the group mean proportion correct for displays without the subject's name (.57). A chi-square test of the null hypothesis that the two theoretical probabilities were identical was performed for each of the 20 subjects. By summing the 20 statistics, $\chi^{2}(20)=12.8, p>.50$, so the null hypothesis was supported.

The group mean proportion correct for the subject's own name when it appeared as a target (.67) was noticeably different from the group mean proportion correct for displays without the subject's name (.57). Again, a chi-square test of the null hypothesis that the two theoretical proportions were identical was done for each of the 20 subjects. By summing the 20 statistics, $\chi^{2}(20)=$ $52.7, p<.001$, so deviations from expectations derived from the null hypothesis were highly significant. Most subjects were more accurate in reporting their own names when they appeared as targets than they were when reporting targets from displays without their own names.
The effect was found for 15 of the 20 subjects, which is significant at the .05 level by a sign test.

Overall proportion correct increased during the experiment, but the relative degrees of difficulty of different types of trials showed little change. For the first 100 trials, group mean proportion correct was .64 for the subject's own name, .49 for the other target in displays with the subject's name as a target, .51 for targets in displays with the subject's name as a distractor, and, again, .51 for targets in displays without the subject's name. For the last 100 trials, the corresponding means were .70 for own name, .59 for the other target in displays with the own name as a target, .61 for targets in displays with the own name as a distractor, and .62 for targets in displays without the own name.

A supplementary analysis was done of performance on the very first trial with the own name as a distractor. A total of 10 subjects were presented with their own names as distractors before seeing their names as targets. The 10 subjects reported a total of 7 targets correctly on the very first trial in which the own name appeared as a distractor. For a comparison, consider the same subjects' scores on trials in which some other name that had not previously been used as a target appeared for the first time as a distractor. Proportion correct for individual targets on such trials averaged .41 . This corresponds to a mean score of 8.2 items correct per 10 trials, which is close to the score of 7 items found for the very first trial with the own name as a distractor. 
Errors. Intrusion errors were rare. Across subjects, the mean number of erroneously reported items per trial averaged $0.12(S D=0.13)$; the mean number of correctly reported items per trial averaged $1.14(S D=0.25)$. Thus, the percentage of errors among the reported items was $9 \%$.

Summed across the 3,200 trials on which a subject's own name was absent from the stimulus display, a total of 399 intrusion errors occurred. Among the 399 intrusions, 11 were reports of the subject's own name, 98 were reports of other names that belonged to the stimulus ensemble but were absent from the stimulus display, 73 were reports of distractors in the display, and 217 were reports of names that did not belong to the stimulus ensemble. Assuming no special bias toward or against ownname reports, the expected proportion of own-name reports among the 109 reports of names in the stimulus ensemble but not in the display was $1 / 16$. Thus, the expected number of own-name reports was $109 / 16=6.8$, which is lower than the number that was observed. However, the overrepresentation of own-name reports in the observed data was not statistically reliable. Subjects 1 and 11 made no erroneous reports of items in the stimulus ensemble. By subjecting individual data for the remaining 18 subjects to binomial tests, converting one-tailed probabilities to values of chi-square for $2 d f$, and summing over subjects (cf. Winer, 1971, p. 49), $\chi^{2}(36)=45.4, p>.25$.

\section{Discussion}

Our first finding seems clear. Presenting a subject's own name as a distractor caused no more interference with report of targets than did presentation of other names as distractors. Apparently, the subject's attention was not automatically attracted by his or her own name.

The second finding fits in with the first one. Proportion correct for a given target was independent of whether the other target in the display was the subject's own name. This finding should be expected if the subject's name attracted no more attention than other names. Conversely, if the subject's own name had attracted more attention than other names, performance should have been lower for targets presented along with the subject's name.

The third finding is in need of explanation. Mean proportion correct was higher for subjects' own names than for other names. Granted that a subject's own name attracted no more attention than other names, nonattentional explanations must be sought. Two nonattentional explanations for the finding suggest themselves. In one, the finding is a sensitivity effect: A subject is more trained and therefore better skilled in perceiving his or her own name than in perceiving other names. In the other explanation, the finding is a bias effect: A subject is biased in favor of either perceiving or reporting his or her own name rather than another name.

Both the sensitivity and the bias explanation are plausible, and they do not exclude each other. Neither explanation can be excluded by considering the pattern of intrusion errors. On the one hand, as predicted by the bias explanation, own-name reports were overrepresented among intrusion errors. On the other hand, intrusion er- rors were rare, and the overrepresentation of own-name reports was not statistically reliable.

The sensitivity and the bias explanation for the finding that mean proportion correct was higher for subjects' own names than for other names share the prediction that a similar effect - a higher hit rate for a subject's own nameshould be found under experimental conditions in which effects of automatic attention attraction are minimal. This prediction was tested in Experiment 2.

\section{EXPERIMENT 2}

Experiment 2 used a single-stimulus identification paradigm. Each stimulus was a common Danish first name, which was briefly presented at fixation. The subject's task was to report the name. On some trials, the subject's own name appeared as the stimulus. Would the hit rate be higher for the subject's own name than for other names?

\section{Method}

Subjects. Ten subjects ( 5 males and 5 females) participated in the experiment. The subjects had normal or corrected-to-normal visual acuity and normal color vision. Their ages ranged from 20 to 29 years, with a mean of 23 years. Every subject had grown up in Denmark bearing a common Danish first name with a length of four to six letters. None of the subjects had participated in Experiment 1, and none were acquainted with the purpose of the experiment.

Names. As in Experiment 1, the stimulus items were common Danish first names with a length of four to six letters. The stimulus ensemble used in the practice session was identical to that used in the practice session of Experiment 1 . Not one of the 20 names in the ensemble was a first name for any of the subjects.

The stimulus set used in the test session consisted of the boys' names Peter, Hans, Erik, Søren, Mikael, Niels, Mads, Thomas, Martin, and Jesper and the girls' names Marie, Inge, Hanne, Tina, Lene, Mette, Louise, Rikke, Julie, and Anne. This group was constructed from the set of 20 names used as the fixed pool in the test session of Experiment 1 by replacing John and Henrik with Søren and Mads. The replacement ensured that the first names of the 10 subjects were all contained in the ensemble.

Displays. Each stimulus display contained a single stimulus item. The item was a four- to six-letter name located at fixation. Shapes and sizes of stimulus letters and names were the same as in Experiment 1.

Each stimulus item was displayed in saturated red (CIE $x y$ coordinates of $.61 / .35)$ on a black $\left(0.0 \mathrm{~cd} / \mathrm{m}^{2}\right)$ screen. It was centered in an open rectangle (fixation box), which was outlined in blue (CIE $x y$ coordinates of $.16 / .08$ ) on the black background. The fixation box was visible at the center of the screen throughout the experiment. It covered an area of $37 \mathrm{~mm}\left(1.8^{\circ}\right)$ vertically by $63 \mathrm{~mm}\left(3.0^{\circ}\right)$ horizontally.

Mask. The mask was a solid rectangle in the same red color as the stimulus item. When the mask was exposed, it filled up the interior blank space of the fixation box, so that the box appeared as a red rectangle with a blue outline against the black background.

Procedure. Apparatus and procedure were the same as in the previous experiment with the following exceptions. Each stimulus display contained only one item, and the subject was instructed to report that item. The duration of the stimulus exposure was $83 \mathrm{msec}$, but the luminance of the item varied among subjects. During the practice session with a subject, the luminance was adjusted so that the subject's proportion of correct reports appeared to be greater than .25 but less than .75 .

Design. The practice session comprised one block of 100 trials: 5 trials with each of the 20 names in the stimulus ensemble designed for practice. The test session comprised four blocks of 100 
trials, each block including 5 trials with each of the 20 names in the test stimulus ensemble. Each practice or test block of 100 trials was administered as four subblocks of 25 trials with short breaks between subblocks. Throughout the experiment, no stimulus item appeared more than once within any sequence of 5 successive trials. Except for the stated constraints, the serial order of trials was random. Randomizations were done independently for the 10 subjects.

\section{Results}

Proportion correct. The main results are shown in Table 2. For $i=1,2, \ldots, 10$, row $i$ shows the name and the results of subject $i$. The results include the proportion of correct reports for trials on which the subject's own name was presented as the stimulus and the proportion of correct reports for all other trials. Group means across the 10 subjects are shown in Row 11.

As can be seen in Table 2, subjects were more accurate in reporting their own than in reporting other names. Group mean proportions were .73 and .46 , respectively. The effect was found for each of the 10 subjects, which is significant at the .001 level by a sign test.

Errors. Averaged across subjects, the observed probability of a correct response was $.47(S D=.19)$. The probability of an intrusion error was .17 $(S D=.07)$. Thus, the percentage of errors among the reported items was $26 \%$.

Summed across the 3,800 trials on which a name other than that of the subject was presented as the stimulus, a total of 651 intrusion errors occurred. Among the 651 intrusions, 13 were reports of the subject's own name, 235 were reports of other names in the stimulus ensemble, and 403 were reports of names that did not belong to the stimulus ensemble. Assuming no special bias toward or against own-name reports, the expected proportion of ownname reports among the 248 erroneous reports of names in the stimulus ensemble was $1 / 19$. Thus, the expected number of own-name reports $(248 / 19=13.1)$ was virtually the same as the number that was observed (13). A statistical analysis of the data for individual subjects supported the null hypothesis that own-name reports occurred among intrusions from the stimulus ensemble with a probability of $1 / 19$. By subjecting the individual data to binomial tests, converting one-tailed probabilities

Table 2

Subjects' Names and Proportions of Correct Reports for These and for Other Names (Experiment 2)

\begin{tabular}{clcc}
\hline & & \multicolumn{2}{c}{ Stimulus } \\
\cline { 3 - 4 } Subject & Name & Own Name* & Other Name† \\
\hline 1 & Peter & .85 & .24 \\
2 & Søren & .90 & .77 \\
3 & Mette & .55 & .33 \\
4 & Julie & .95 & .66 \\
5 & Inge & .85 & .56 \\
6 & Erik & .80 & .27 \\
7 & Anne & .50 & .38 \\
8 & Thomas & 1.00 & .66 \\
9 & Louise & .45 & .28 \\
10 & Mads & .45 & .41 \\
Group & & .73 & .46 \\
\hline
\end{tabular}

* Proportions are based on 20 cases per subject. †Proportions are based on 380 cases per subject. to values of chi-square for $2 d f$, and summing over subjects, $\chi^{2}(20)=24.2, p>.45$.

\section{Discussion}

In Experiment 1, presentation of the subject's name as a distractor caused no more interference with report of targets than did presentation of other names as distractors. Apparently, visual attention was not automatically attracted by the subject's own name. However, presentation of the subject's name as a target yielded improvement in performance: Accuracy was enhanced for the subject's name, and the gain seemed not accompanied by any loss in the accuracy of reporting targets that appeared along with the subject's name. This finding seemed to call for a nonattentional explanation by which subjects are (1) better skilled in perceiving their own names or (2) biased toward perceiving or reporting their own names as opposed to other names.

The nonattentional explanation predicted that the finding of a higher hit rate for a subject's own name should be replicable under conditions in which effects of automatic attention attraction are eliminated. We attempted to create such conditions in Experiment 2 by using a singlestimulus identification paradigm with the stimulus presented at fixation (i.e., without any position uncertainty). The finding of a higher hit rate for a subject's own name was replicated, so a nonattentional explanation for this effect was supported.

Intrusion errors were relatively frequent in Experiment 2 , and the pattern of intrusion errors was instructive. The pattern showed no overrepresentation of own-name reports. This result suggests that the superior hit rate for a subject's own name was a sensitivity effect and not a bias effect. Apparently, subjects were better skilled in perceiving their own names than other names.

\section{GENERAL DISCUSSION}

The reported experiments provide evidence that under the conditions employed in Experiment 1, visual attention was not attracted by a subject's own name. The conclusion rests on the finding that no impediment occurred in the processing of targets by presenting a subject's own name instead of another name as a distractor. The boundary conditions of the null effect are not known, but some speculations are in order.

Experiment 1 investigated partial report based on a clear difference in color between targets (red) and distractors (white). Many studies of partial report (e.g., Bundesen, Pedersen, \& Larsen, 1984; Bundesen, Shibuya, \& Larsen, 1985) have shown that selection based on a clear difference in color is highly efficient. With highly efficient selection of targets, few distractor words may have been recognized in Experiment 1 . If the selection criterion had been changed so that selection of targets had become less efficient, more distractor words might have been recognized, and recognition of own names among the distractors might have caused our null effect to break down. 
In terms of Bundesen's (1990) theory, the null effect suggests that attentional weights were computed independently of any contact between words in the stimulus display and lexical entries in memory. The results are consistent with a hypothesis that the initial allocation of attention to items in a visual display is independent of any contact between stimulus words and lexical entries. However, the generality of our findings may be questioned. It is conceivable that lexical information would have affected computations of attentional weights if viewing conditions had been improved so that stronger and earlier contact had been made between stimulus words and lexical entries. ${ }^{3}$

Our results fit in with Logan's (1992) findings suggesting that automatic attention responses cannot be developed to multiletter words. As noted by Logan, Shiffrin and Schneider (1977) presented two main pieces of evidence for development of automatic attention responses to single letters or digits. The first piece of evidence was that effects of display size nearly vanished when subjects were trained consistently in visual search for particular letters or digits. The second piece of evidence was described in our introduction: After consistent training in search for particular letters or digits, presentation of one of these letters or digits as a distractor impeded detection of targets in the same display much more strongly than did presentation of other letters or digits.

In contrast to the first piece of evidence for development of automatic attention responses to single letters or digits, Logan (1992) found little or no reduction in effect of display size when subjects were trained consistently in visual search for particular five-letter words and nonwords among other five-letter strings. In contrast to the second piece of evidence, we found no more impediment in the processing of targets by presenting a subject's own name rather than another name as a distractor. A possible explanation for the contrasts between the findings with single letters and digits and the findings with multiletter words is that visual attention can be attracted by individual alphanumeric characters but not by shapes as complex as multiletter words.

\section{REFERENCES}

ALLPORT, D. A. (1977). On knowing the meaning of words we are unable to report: The effects of visual masking. In S. Dornic (Ed.), Attention and performance VI (pp. 505-534). Hillsdale, NJ: Erlbaum.

BroadBent, D. E. (1958), Perception and communication. London: Pergamon.

BundeSEN, C. (1987). Visual attention: Race models for selection from multielement displays. Psychological Research, 49, 113-121.

Bundesen, C. (1990). A theory of visual attention. Psychological Review, 97, 523-547.

BUNDESEN, C. (1993). The relationship between independent race models and Luce's choice axiom. Journal of Mathematical Psychology, 37, 446-471.

Bundesen, C., Pedersen, L. F., \& Larsen, A. (1984). Measuring efficiency of selection from briefly exposed visual displays: A model for partial report. Journal of Experimental Psychology: Human Perception \& Performance, 10, 329-339.

Bundesen, C., Shibuya, H., \& Larsen, A. (1985). Visual selection from multielement displays: A model for partial report. In M. I. Posner \& O. S. M. Marin (Eds.), Attention and performance XI (pp. 631649). Hillsdale, $\mathrm{NJ}$ : Erlbaum.
Christie, J., \& Klein, R. (1995). Familiarity and attention: Does what we know affect what we notice? Memory \& Cognition, 23, 547-550.

Czerwinski, M., Lightfoot, N., \& Shiffrin, R. M. (1992). Automatization and training in visual search. American Journal of Psychology, 105, 271-315.

Deutsch, J. A., \& Deutsch, D. (1963). Attention: Some theoretical considerations. Psychological Review, 70, 80-90.

Duncan, J. (1980). The locus of interference in the perception of simultaneous stimuli. Psychological Review, 87, 272-300.

Duncan, J. (1985). Visual search and visual attention. In M. I. Posner \& O. S. M. Marin (Eds.), Attention and performance XI (pp. 85-105). Hillsdale, NJ: Erlbaum.

Folk, C. L., \& Remington, R. W. (1996). When knowledge does not help: Limitations on the flexibility of attentional control. In A. F. Kramer, M. G. H. Coles, \& G. D. Logan (Eds.), Converging operations in the study of visual selective attention (pp. 271-295). Washington, DC: American Psychological Association.

HOFFMAN, J. E. (1978). Search through a sequentially presented visual display. Perception \& Psychophysics, 23, 1-11.

Johnston, W. A., Hawley, K. J., \& Farnham, J. M. (1993). Novel popout: Empirical boundaries and tentative theory. Journal of Experimental Psychology: Human Perception \& Performance, 19, 140153

Kahneman, D., \& Treisman, A. (1984). Changing views of attention and automaticity. In R. Parasuraman \& D. R. Davies (Eds.), Varieties of attention (pp. 29-61). New York: Academic Press.

LABERGE, D., \& Brown, V. (1989). Theory of attentional operations in shape identification. Psychological Review, 96, 101-124.

LOGAN, G. D. (1992). Attention and preattention in theories of automaticity. American Journal of Psychology, 105, 317-339.

Moray, N. (1959). Attention in dichotic listening: Affective cues and the influence of instructions. Quarterly Journal of Experimental Psychology, 11, 56-60.

MORAY, N. (1969). Attention: Selective processes in vision and hearing London: Hutchinson.

Norman, D. A. (1968). Toward a theory of memory and attention. Psychological Review, 75, 522-536.

SCHNEIDER, W. (1985). Toward a model of attention and the development of automatic processing. In M. I. Posner \& O. S. M. Marin (Eds.), Attention and performance $X I$ (pp. 475-492). Hillsdale, NJ: Erlbaum.

Schneider, W., Dumais, S. T., \& ShIfFrin, R. M. (1984). Automatic and control processing and attention. In R. Parasuraman \& D. R. Davies (Eds.), Varieties of attention (pp. 1-27). New York: Academic Press.

SChNEIDER, W., \& SHIFFrin, R. M. (1977). Controlled and automatic human information processing: I. Detection, search, and attention. Psychological Review, 84, 1-66.

ShIBUYA, H. (1993). Efficiency of visual selection in duplex and conjunction conditions in partial report. Perception \& Psychophysics, 54, 716-732.

Shibuya, H., \& Bundesen, C. (1988). Visual selection from multielement displays: Measuring and modeling effects of exposure duration. Journal of Experimental Psychology: Human Perception \& Performance, 14, 591-600.

ShIFFRIN, R. M., \& CZERWINSKI, M. P. (1988). A model of automatic attention attraction when mapping is partially consistent. Journal of Experimental Psychology: Learning, Memory, \& Cognition, 14, 562-569.

Shiffrin, R. M., \& Dumais, S. T. (1981). The development of automatism. In J. R. Anderson (Ed.), Cognitive skills and their acquisition (pp. 111-140). Hillsdale, NJ: Erlbaum.

Shiffrin, R. M., Dumais, S. T., \& SchneIder, W. (1981). Characteristics of automatism. In J. Long \& A. [D.] Baddeley (Eds.), Attention and performance $I X$ (pp. 223-238). Hillsdale, NJ: Erlbaum.

Shiffrin, R. M., \& SCHNEIDER, W. (1977). Controlled and automatic human information processing: II. Perceptual learning, automatic attending, and a general theory. Psychological Review, 84, 127-190.

THEEUWES, J. (1995). Temporal and spatial characteristics of preattentive and attentive processing. Visual Cognition, 2, 22l-233.

THEEUWES, J. (1996). Perceptual selectivity for color and form: On the nature of the interference effect. In A. F. Kramer, M. G. H. Coles, \& G. D. Logan (Eds.), Converging operations in the study of visual selective attention (pp. 297-314). Washington, DC: American Psychological Association. 
Treisman, A. M., \& Gelade, G. (1980). A feature-integration theory of attention. Cognitive Psychology, 12, 97-136.

VAN DER HEIJDEN, A. H. C. (1981). Short-term visual information forgetting. London: Routledge \& Kegan Paul.

VAN DER HEIJDEN, A. H. C. (1992). Selective attention in vision. London: Routledge.

VAN DER HeIJDEN, A. H. C. (1993). The role of position in object selection in vision. Psychological Research, 56, 44-58.

WINER, B. J. (1971). Statistical principles in experimental design (2nd ed.). New York: McGraw-Hill.

YANTIS, S. (1993). Stimulus-driven attentional capture. Current Directions in Psychological Science, 2, 156-161.

YANTIS, S. (1996). Attentional capture in vision. In A. F. Kramer, M. G. H. Coles, \& G. D. Logan (Eds.), Converging operations in the study of visual selective attention (pp. 45-76). Washington, DC: American Psychological Association.

\section{NOTES}

1. The theory of visual attention proposed by Bundesen (1990; see also Bundesen, 1987, 1993; Shibuya \& Bundesen, 1988) is neutral on whether multiletter words can have pertinence and attract attention, but the issue is a critical one in many other theories. In early-selection theories (e.g., Broadbent, 1958; Kahneman \& Treisman, 1984; LaBerge \& Brown, 1989; Moray, 1969; Treisman \& Gelade, 1980), attentional selection takes place before pattern recognition. Early selection is based on simple physical features (e.g., location, color, or length) extracted by prerecognition processes. It cannot be based on the complex shape of a multiletter word or on word meaning. In late-selection theories (e.g., Allport, 1977; Deutsch \& Deutsch, 1963; Duncan, 1980, 1985; Hoffman, 1978; Norman, 1968; Schneider, 1985; Shiffrin \& Schneider, 1977), attentional selection takes place only after pattern recognition. It can be based on word shape or word meaning as well as on simpler stimulus characteristics (but see van der Heijden, 1981, 1992, 1993).

For recent work on attentional capture, see Christie and Klein (1995), Folk and Remington (1996), Johnston, Hawley, and Farnham (1993), Theeuwes $(1995,1996)$, and Yantis $(1993,1996)$.

2 . The occurrence of a name with the same initial letter as the subject's name should make it possible to discriminate attentional attraction caused by presentation of the subject's name from attentional attraction caused by presentation of the initial letter of the subject's name.

3 . The generality of our findings across different types of stimulus material should also be investigated. All items in our displays were common Danish first names. One reviewer pointed out that all of the names might represent important personal acquaintances for all of the subjects. He suggested that a special tendency to attend to the own name might appear if the own name was presented among low-frequency instead of high-frequency names. Another reviewer pointed out that first names were less unique than last names. He suggested that a tendency to attend to the own name might appear if last names were used instead of first names.

(Manuscript received March 13, 1996; revision accepted for publication July 29,1996 .) 